\title{
Deploying Virtual Product Dissection Lesson Modules in Introductory Engi- neering Classrooms: A Research-Driven Approach
}

\section{Dr. Elizabeth Marie Starkey, Pennsylvania State University}

Elizabeth Starkey is a Post-Doctoral Scholar in the School of Engineering Design Technology and Professional Programs at the Pennsylvania State University. She received her Ph.D. and M.S. in Industrial Engineering from the Pennsylvania State University and her B.S. in Computer Engineering and Applied Mathematics from Elizabethtown College.

\section{Dr. Scarlett Rae Miller P.E., Pennsylvania State University}

Scarlett Miller is an Associate Professor of engineering design and industrial engineering at the Pennsylvania State University. She received her Ph.D. in industrial engineering from the University of Illinois and her M.S. and B.S. in industrial engineering from the University of Nebraska.

\section{Prof. Samuel Todd Hunter}




\section{Deploying Virtual Product Dissection Lesson Modules in Introductory Engineering Classrooms: A Research Driven Approach}

\section{Abstract}

Product dissection is a problem-based learning activity that is often integrated into engineering courses in order to help students learn to systematically disassemble and analyze a product and all of its parts. Product dissection was first introduced into engineering education in the early 1990's and has since been a staple in introductory courses. Although many studies have been conducted in relation to product dissection, research has not been systematic, leaving us to question how variations in product dissection impact learning, creativity, or both for students when used in the classroom. To fill this gap, our research group has conducted numerous studies over the last four years in order to systematically investigate variations in deployment of product dissection in an engineering classroom. Using the findings from these studies, we have developed a virtual product dissection module and deployed it in an introductory engineering course. We provide recommendations for the use of product dissection in the classroom and provide insights into the deployment of this module. The results from the case study that follows indicate that students found the dissection modules helped them understand how the products worked and that it could be used to inspire creative ideas during idea generation. Although the students found the dissection useful, some of them struggled to see how their dissected product related to the design task they were completing. These results are used for continued development of the product dissection classroom lesson modules.

\section{Introduction}

Deconstructing and reconstructing artifacts into new creations is an important facet of innovation. Whether it is deconstructing the Shakespearean play Hamlet and reconstructing it into the Disney film The Lion King [1] or deconstructing a nerf gun and reconstructing it into a device that can froth milk, this deconstruction and reconstruction process is integral to innovation, since design examples are utilized heavily in the design process [2]. In order to guide this discovery process in engineering education, academics have relied on product dissection or the systematic disassembly and analysis of a product and all of its parts [3-6]. This method of mechanical dissection was first introduced by Sherri Sheppard in the early 1990's when she identified a formal educational process for taking apart a product to understand how it works, which provided the basis for the implementation of a course utilizing product dissection to expose students "to the language of the mechanical things that surround us" [3] (pg. 2). Due to the success of this work, product dissection in engineering education has become more prominent in introductory engineering courses [7].

While prior work has also brought awareness to the potential learning benefits of physical product dissection, there are still many obstacles that keep dissection from being adopted on a wider scale $[8,9]$. For instance, there is a wide range of the products dissected in these courses; early adopters dissected anything from a see-and-say children's toy to a four stroke engine [4, 5, 10]. In addition, the material cost and the space and safety requirements of the laboratories also hinder the large scale deployment $[11,12]$. For instance, if the entire freshmen engineering class at a large public university with around 2000 students each year were each to dissect an 
inexpensive electric hand mixer ( $\$ 14.89$ from amazon.com, see Appendix A for details), this would cost about $\$ 29,780$ each year. In addition, it would create 3,100 pounds of waste per year (1.55 pounds per mixer).

Because of this, virtual product dissection has been offered as an alternative method for deployment in engineering classrooms [13] to reduce this cost and waste burden. However, early studies in virtual product dissection found that the usability of the repository system [14] and the cost of developing CAD models of products [13] was prohibitory to the advancement of these systems for use in the classroom. Thankfully, there has been significant technological advancements over the last 10 years which are making virtual dissection more attainable on a large scale. Specifically, SolidWorks eDrawings software has made viewing 3D models seamless, and websites like grabcad.com provide open source access to numerous virtual models. With lower cost 3D scanners available on the market, the cost for developing models has also decreased. Although the startup cost of creating virtual models is significantly more than buying a single physical model, the virtual model can be used and reused an unlimited number of times, while a single physical model often cannot be reused (see table 1 for a breakdown of cost between environments). To create the virtual model of this hand mixer, a freelance CAD modeler was contacted for a quote on the cost to reverse engineer the product, giving an estimate of 40 hours at a cost of $\$ 12$ per hour, for a total cost of $\$ 480$ (no formalized quote was provided). In addition, a 3D scanning and reverse engineering company was contacted for a quote to scan and reverse engineer this hand mixer, giving an estimate of \$6,185 (see Appendix A for detailed quote). While both numbers are much higher than the cost of buying one electric hand mixer, the cost ratio of the physical model to the virtual model evens out after 32 mixers are dissected for the low estimate and 413 mixers are dissected for the high estimate. This means the virtual model will pay for itself after only a 5th of 1 year's worth of product dissecting for freshmen. While some virtual environments have a limit on the number of users that they can handle at one time [15], for the purposes of this research we use SolidWorks eDrawings, a free locally run software, and open source models that are freely available for download. Therefore, there is no practical limitation to the number of people who can dissect a virtual product at the same time. In addition, with the democratization of design and websites like grabcad.com, some of these expenses can now be mitigated, making virtual dissection an important problem to investigate. Table 1: Cost Break Down for Virtual Versus Physical Models for 1 Year of Penn
State Freshmen to Dissect a Hand Mixer

\begin{tabular}{|l|r|r|r|}
\hline & Virtual - Freelance & Virtual - 3D Scanner & Physical \\
\hline Cost for model & $\$ 480$ & $\$ 6185$ & $\$ 14.89$ per model \\
\hline $\begin{array}{l}\text { Cost multiplier } \\
\text { for } 2,000 \text { students }\end{array}$ & $\begin{array}{r}1 \text { (Unlimited number } \\
\text { of uses/reuses) }\end{array}$ & $\begin{array}{r}\text { (Unlimited number of } \\
\text { uses/reuses) }\end{array}$ & $\begin{array}{r}\text { 2,000 (1 per } \\
\text { student) }\end{array}$ \\
\hline Total cost & $\$ 480$ & $\$ 6185$ & $\$ 29,780$ \\
\hline Waste Created & $1.55 \mathrm{lbs}$ & $1.55 \mathrm{lbs}$ & $3,100 \mathrm{lbs}$ \\
\hline
\end{tabular}




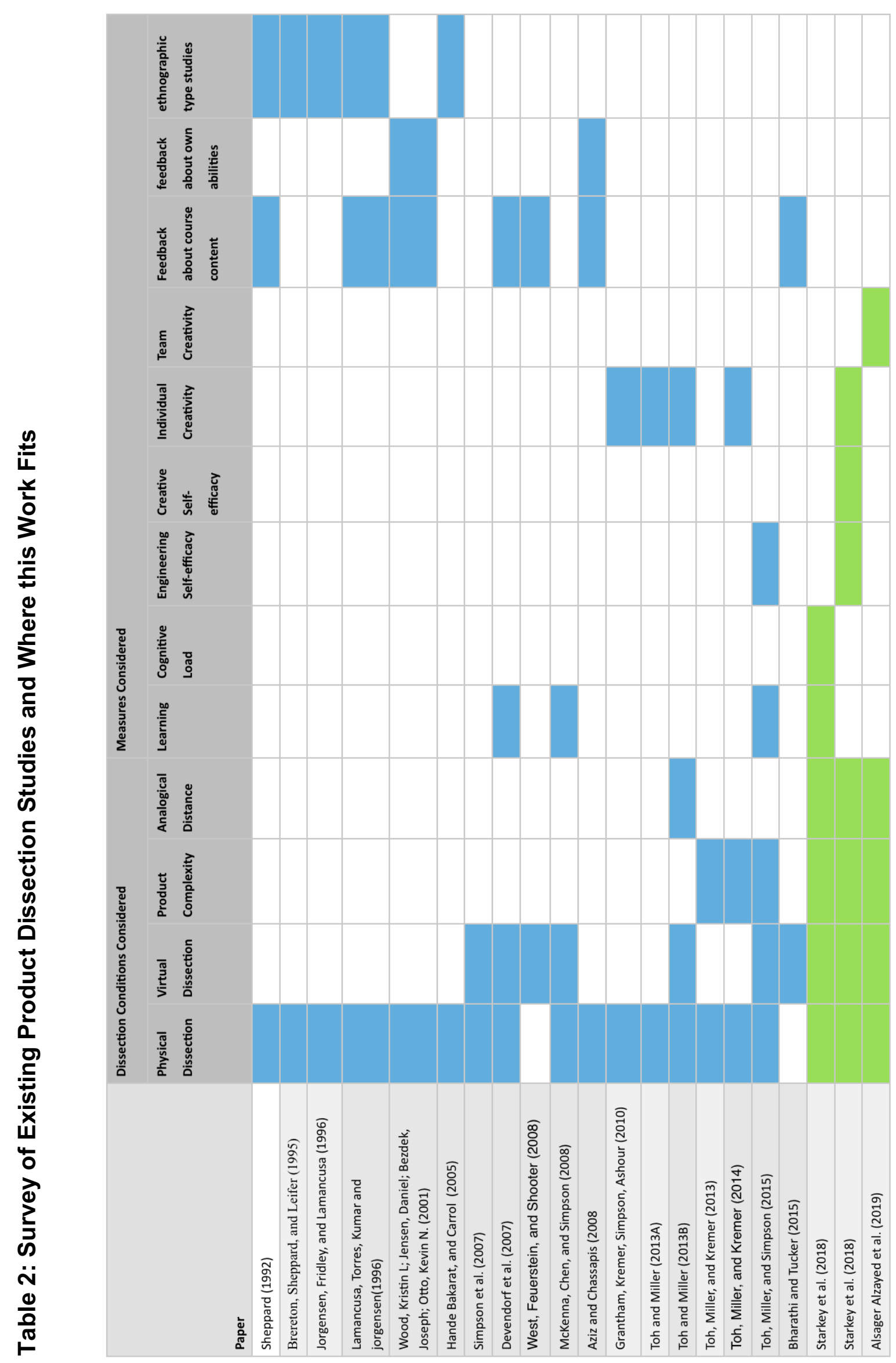


In addition to exploring how products are dissected, the way that product dissection is used as a classroom experience differs noticeably between studies. Early work in product dissection focused on the benefits of learning how products work $[3,4,16]$, while more recent work has investigated how product dissection may be beneficial during product redesign as a source of inspiration or to provide a jumping off point for creative idea generation [17-20]. The use of product dissection as a tool in product redesign is important, because a goal of engineering education is to teach students how to apply the design process to improve their ability to utilize innovative processes in industry. [21, 22]. Through the use of project based learning, educators can integrate product dissection into the design process and promote creativity; both of which are part of ASEE's core educational values [23] and emphasized by industry [24]. While it is important to investigate creative outcomes, these outcomes also need to be contextualized in engineering education. This is particularly important in light of a recent study, which showed that freshmen produced more novel concepts than senior engineering students, with no differences in the quality of their designs [25]. These results suggest that the engineering education process may be reducing the creativity of our students. Because of this, research is necessary in order to understand what activities help engineering students be more creative [25, $26]$ and whether there is a connection between learning and creativity. One way to measure student progress is through the use of self-efficacy surveys to measure one's belief in their engineering [27] and creative [28] ability, since self-efficacy is a strong predictor of future behavior [29].

While Table 2 identifies the prior work in the area of product dissection, the implementation of product dissection in the engineering classroom has not been systematic, leaving us to question how variations in product dissection impact learning, creativity, or both for students when used in the classroom. In order to fill this gap in the literature, our research group has conducted numerous studies over the last four years in order to systematically investigate variations in deployment of product dissection in an engineering classroom. Through these studies, a research driven product dissection lesson module was developed and deployed in an introductory engineering course. This paper serves to disseminate the product dissection lesson module as well as to provide insights into the sentiment of students from the deployment of these modules in the classroom.

Over the past four years, our research group has focused on developing a theoretical understanding of the factors of product dissection that impact learning and creativity, see Table 3 for summary of findings. As demonstrated in Table 2, our work builds on the work of others in that it holistically investigates factors that have individually been established as important to the deployment of product dissection in a systematic fashion. However, something that was missing was the translation of these rigorous experimental results into the development of an educational intervention. This section serves to highlight the findings of this prior work on the impact of dissection modality, complexity, and analogical distance, and identify how these results can be articulated into an educational, research-based intervention. 


\section{Table 3: Summary of Main Findings from 4 Years of Dissection Research}

\begin{tabular}{|c|c|c|c|}
\hline & Learning & Individual Creativity & Team Creativity \\
\hline $\begin{array}{l}\text { Modality } \\
\text { (virtual or } \\
\text { physical) }\end{array}$ & $\begin{array}{l}\text { No differences were found } \\
\text { in Student Learning } \\
\text { Assessment (SLA) post- } \\
\text { test scores. } \\
\text { Different types of } \\
\text { cognitive load were used, } \\
\text { but overall load was the } \\
\text { same. }\end{array}$ & $\begin{array}{l}\text { There were no } \\
\text { differences in creativity } \\
\text { between virtual and } \\
\text { physical dissection. }\end{array}$ & $\begin{array}{l}\text { Virtual product dissection } \\
\text { encouraged the exploration of } \\
\text { more novel designs for both first- } \\
\text { year and senior engineering design } \\
\text { teams. } \\
\text { Physical dissection helped in the } \\
\text { exploration of a larger variety and } \\
\text { quantity of ideas for senior teams, } \\
\text { while virtual dissection } \\
\text { encouraged the same in first-year } \\
\text { teams. }\end{array}$ \\
\hline Complexity & $\begin{array}{l}\text { Those dissecting relatively } \\
\text { complex products scored } \\
\text { lower on their SLA than } \\
\text { those dissecting relatively } \\
\text { simple products. }\end{array}$ & $\begin{array}{l}\text { There were no } \\
\text { differences in creativity } \\
\text { between relatively } \\
\text { simple and relatively } \\
\text { complex products. }\end{array}$ & \\
\hline $\begin{array}{l}\text { Analogical } \\
\text { Distance/ } \\
\text { Product } \\
\text { Power } \\
\text { Source }\end{array}$ & $\begin{array}{l}\text { Those dissecting the } \\
\text { manually powered } \\
\text { products scored lower on } \\
\text { their SLA than those } \\
\text { dissecting electrically } \\
\text { powered products. }\end{array}$ & $\begin{array}{l}\text { There were no } \\
\text { differences in creativity } \\
\text { between manually and } \\
\text { electrically powered } \\
\text { products. } \\
\text { Creative self-efficacy } \\
\text { increased more in the } \\
\text { analogically near } \\
\text { condition. }\end{array}$ & $\begin{array}{l}\text { Dissecting a wider variety of } \\
\text { products helped both first-year and } \\
\text { senior teams explore a larger } \\
\text { solution space. }\end{array}$ \\
\hline $\begin{array}{l}\text { Dissection } \\
\text { Activity }\end{array}$ & $\begin{array}{l}\text { The Bill of Materials } \\
\text { (BOM) and Functional } \\
\text { Layout Diagram (FLD) } \\
\text { had no correlation with the } \\
\text { score on the SLA. }\end{array}$ & & \\
\hline
\end{tabular}




\section{Dissection Modality Physical versus Virtual}

One of the main drivers for this research thread was to look at the impact of the modality of dissection on student learning and creativity. As such, our prior research sought to systematically compare virtual and physical dissection and its impact on student learning and creativity. One of the most important findings of this work was that virtual dissection can serve as a proxy for physical dissection, not only as a means for promoting creativity, but also as a way for students to learn about how products work [30,31]. This finding is supported by results from [30], where students did not score differently on their Student Learning Assessment (SLA) posttests, nor did overall cognitive load change between dissection modalities (virtual or physical). In addition, this finding is supported by results from [31], where student Creative SelfEfficacy (CSE) and the creativity of a student's idea set did not differ between dissection modalities. While results from these two studies support the use of either physical or virtual dissection for promoting creativity and learning at the individual level, results from [32] indicate that that virtual product dissection encourages novelty in design teams, highlighting the merits of virtual dissection in place of physical dissection in the classroom.

While these results hold virtual dissection in a positive light, other results show a mixed message when it comes to modality. For instance, results showed more variety and higher quantity of ideas were explored by seniors when dissecting physically, while the opposite was true of first-year students. This indicates that different methods may be more useful to students with varying levels of prior knowledge. In addition to the benefits of virtual dissection outlined by the research results, virtual dissection comes with the benefit of accessibility. Due to the increased accessibility and lower cost of virtual models that are available at no cost to anyone with a computer, students who are in a traditional or distance classrooms can engage in virtual dissection without buying a physical product. These findings led to the development of a virtual dissection library and deployment of the dissection module virtually.

\section{Dissection Product Complexity and Analogical Distance}

In addition to identifying the impact of the modality of the dissection activity, we also wanted to assess the impact of the product dissected. Through the course of this research, four different products were investigated with varying levels of complexity and analogical distance from a milk frother design task. The results from this research revealed that when it comes to understanding products, the product dissected has no impact on increases in student Engineering Self-Efficacy, but more complex products may take additional time to dissect and understand fully [30]. When dissecting a product for use during redesign, the results also showed that variations in the product dissected did not impact increases in the creativity of the idea set, but students gained the most Creative Self-Efficacy (CSE) when dissecting analogically near products [31]. Finally, the results from [32] support the use of any product for increasing novelty, and show that if dissecting in teams, students should dissect different products in order to increase the solution space explored. These findings lead to the elimination of restriction on the product chosen for dissection at the individual level, with the restriction that team members dissect different products. 


\section{Dissection Activity}

A final point of question in our research was the activity completed during the dissection activity. During this research, the dissection activity was paired with the completion of a functional layout diagram (FLD) and a bill of materials (BOM). Through this research, findings suggest that student conceptual understanding was not related to their completion percentage of the FLD or BOM [30]. Keeping this in mind, the product dissection module was developed to be used without an FLD or BOM and was instead paired with a new activity that broke down the activity similarly to how it was broken down in the SLA. In addition, a within-subjects study of the use of product dissection to aid in creative idea generation, students generated ideas, then dissected a product, and then generated more ideas. The results from this study found that students expanded the solution space they explored after dissecting [33], which led to the use of two idea generation sessions in the dissection lesson module.

\section{Using these findings to develop educational interventions}

Figure 1 presents a flowchart overview of when different types of dissection activities are appropriate for learning and creativity in the classroom based on the results from this prior work. Specifically, the flowchart shows that it does not matter what product students dissect if the educator is focused on improving student ESE or creativity. However, when educators are intending to use dissection to increase CSE, students should be pointed towards products that are analogically near to their target domain. It is important to note that a product that is analogically near should not be a literal copy or example of an existing product that solves the problem and is already on the market. An analogically near product should be a product that can be easily transferred from the domain it was created for to the target domain and should be analogically near in the categories of (1) general appearance, (2) mechanical movement, and (3) use and application [31].

\section{Figure 1: Flow Chart of What Types of Dissection to Use in the Classroom and When to Use them}

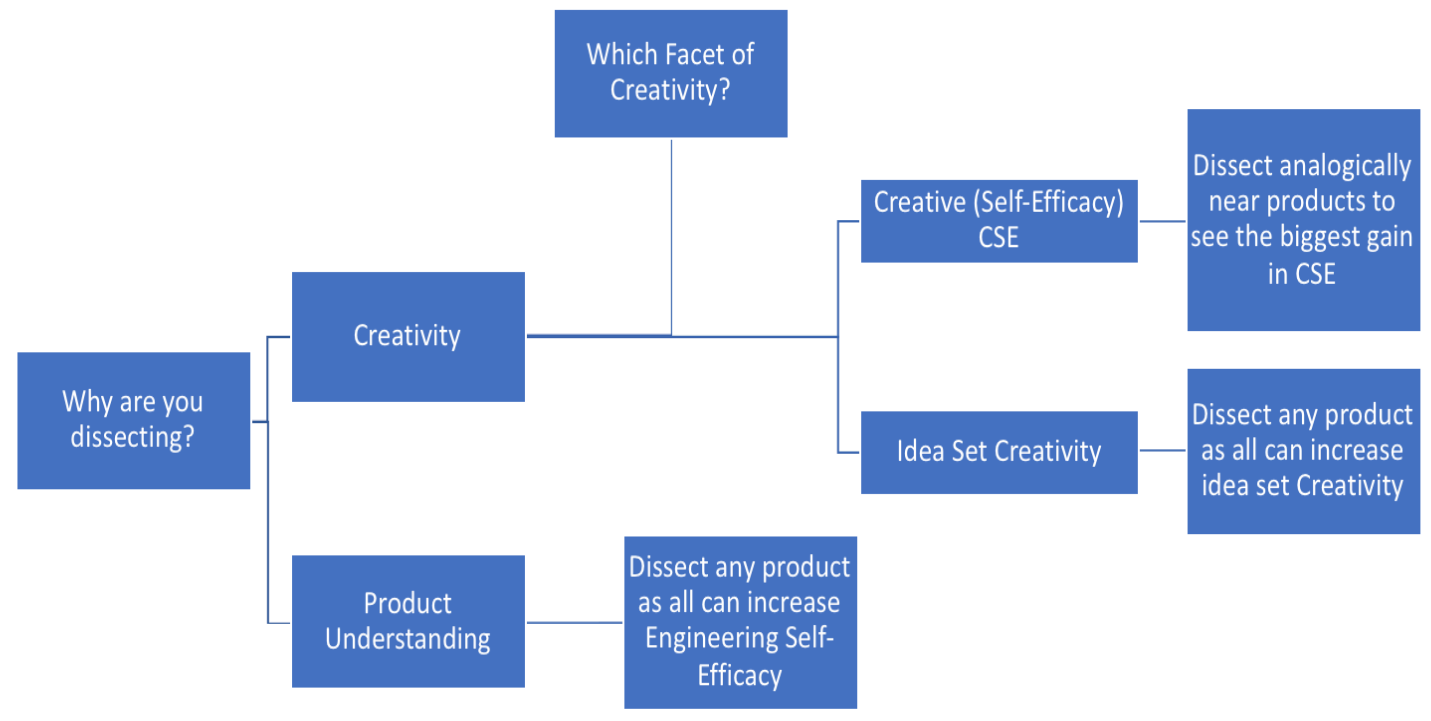




\section{Research-Based Virtual Dissection Module and Case Study}

As an example of how to translate these research results into an educational intervention, we present a virtual dissection module developed to help students develop creative ideas and provide discussion on the impact of the type of product dissected on creativity. While the module was developed to be deployed over a 1.5 hour time period, see Figure 2, it can be easily broken into several class periods or instructors can take aspects of the module to utilize as needed for their educational goals. The remainder of this section presents the resources needed to utilize this module, the module's lesson plan, and a case study of the modules deployment in a first-year introduction to engineering course.

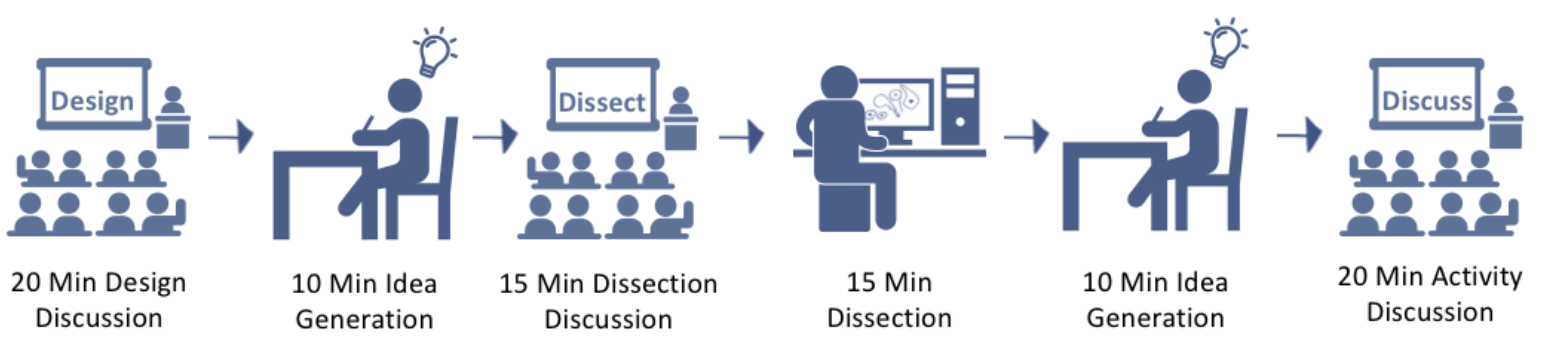

Figure 2: Timeline of 1.5 Hour Virtual Product Dissection Lesson Module

\section{Module Resources}

The resources needed to deploy this module are provided at www.engr.psu.edu/productdissection, referred to hereafter as the 'product dissection website'. This website includes: instructor resources (PowerPoint presentation, video links, discussion questions, and product dissection keys), student resources (product dissection library, dissection activities), and research evidence (papers published on dissection), see Figure 3 for an example website page. However, in order to complete this module, students need access to a computer or tablet that has SolidWorks eDrawings [34] installed; importantly, this is a free software program and is available on both Apple and Windows computers.

\section{Module Lesson Plan Breakdown}

The module begins with a 20 minute discussion on the engineering design process with a focus on conceptualization and creativity. This discussion is anchored in a PowerPoint presentation, which has a link to a 7:41 YouTube video (https://www.youtube.com/watch?v=fuaaXMp35NI) developed by the researchers that introduces students to the importance of creativity in engineering design through a series of engineering examples and creativity exercises like an alternative use test [35]. Next, students are given a design task either designated by the instructor or selected from the product dissection website and students are given 10 minutes to individually come up with ideas for the design task. Next, students are introduced to product dissection through a 2:58 minute video (https://www.youtube.com/watch?v=9UQbSIK5SdQ) developed by the researchers that discusses what product dissection is and how you perform dissection. It then introduces the 
students to virtual dissection. Following this, a 2:22 minute video

(https://www.youtube.com/watch?v=jJP5AnTHGhs) developed by the researchers is used to describe how to use eDrawings for virtual dissection. Students are then provided with the link to the product dissection website and asked to select 1 of the 11 virtual products for dissection. They are then given 15 minutes to dissect the product and complete a dissection activity sheet (www.engr.psu.edu/productdissection/instructorsupport) that encourages students to identify ways they could utilize the product they dissect in their redesign by asking them to identify application opportunities. Following the dissection activity, students are given 10 minutes to come up with additional ideas for the design prompt. As a final step, the students are led through a 20-minute discussion activity led through the PowerPoint presentation that focuses on the usefulness of the product dissected for the activity, the impact of the complexity of the product dissection on design outcomes, and the reuse of features from the product dissected in the design ideas. The module is culminated in a student-reflection which captures their understanding of the dissection lesson.

\section{Case Study of Module Deployment}

In order to identify student perceptions on the utility of the dissection activity, the module was deployed in a first-year introduction to engineering design class at a large northeastern university. Specifically, 29 students (21 males, 8 females) participated in an IRB approved study on the use of product dissection modules in engineering education. The module described in the previous section was used, and the design prompt provided to the students was "Upper

Figure 3: Excerpt from Virtual Product Dissection Website

\section{Learn Through Product Dissection}

Our team has developed virtual product models that can be downloaded here. Use our models with the SolidWorks eDrawings software to learn more about how products work and gain design inspiration for your design project.

Download eDrawings

\section{Product Models}

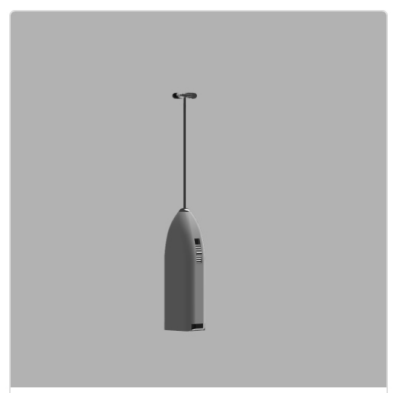

Milk Frother 1

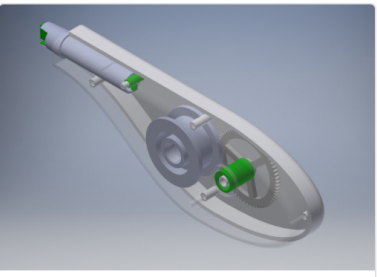

Correction Tape Dispenser

$\pm$

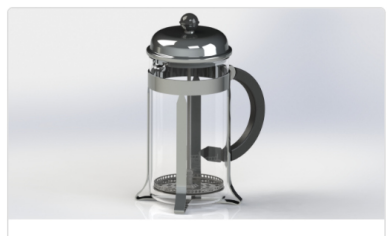

French Press

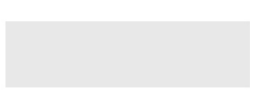

$\pm$

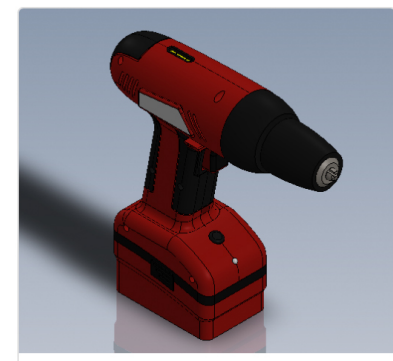

Cordless Drill 
management has put your team in charge of developing a concept for a new innovative math manipulative that will help k-12 students visualize and physically experience a specific mathematical concept of your choosing. Your product must be low cost, different than other products on the market, be useful to the target user, and be aesthetically pleasing." The student reflection activity was used to capture the students' opinions of the activity. For the purposes of the case study, we also included a Likert scale survey from 1 (do not agree) to 7 (completely agree) on the following items: 1) product dissection helped me understand how a product works, 2) product dissection can help inspire creative ideas during idea generation), and 3) I was able to draw inspiration from the product I dissected during idea generation.

In order to understand if the students agreed with the above statements, Wilcoxson Signed Rank tests were used to compare student response to the hypothesized median of 4 (the midpoint of the scale). The results showed that the students believed that the dissection modules helped them understand how the products worked $(p<0.005$, Median $=6)$ and that it could be used to inspire creative ideas during idea generation $(\mathrm{p}<0.005$, Median $=5)$. However, the students neither agreed nor disagreed that the activity helped them draw inspiration for the design task they were provided with ( $p=0.869$, Median $=4)$. This is likely due to the design task being deployed in the class (a math manipulative task); while half of the students reported that they were able to directly apply aspects of the dissected product to their design task, the other half struggled with this application. For example, participant 21 said, "the nerf gun was a little too complicated to incorporate the inner mechanism into a simple math manipulative." This was mimicked in the class discussion when students emphasized that the design problem (to design a math manipulative) didn't require moving parts and that the dissection would have been more useful if they were designing a mechanical/electrical product. On the other hand, half of the participants were able to make the leap between their product and the design task. For example, participant 3 said that, "The product I chose used gears so I began to brainstorm ideas for a manipulative with gears." Similarly, participant 7 said it allowed him/her to "come up with new ideas for our project." This is demonstrated in figure 4, where participant 3 and 7 utilized gears in their final designs after dissecting. In addition to directly transferring parts or concepts to create new ideas, students also thought that the product dissection helped them to think differently about the problems. Specifically, participant 18 said, "it did change my mindset and got me thinking creatively" and participant 11 said, "It made me think of all of the details that need to go into one product."
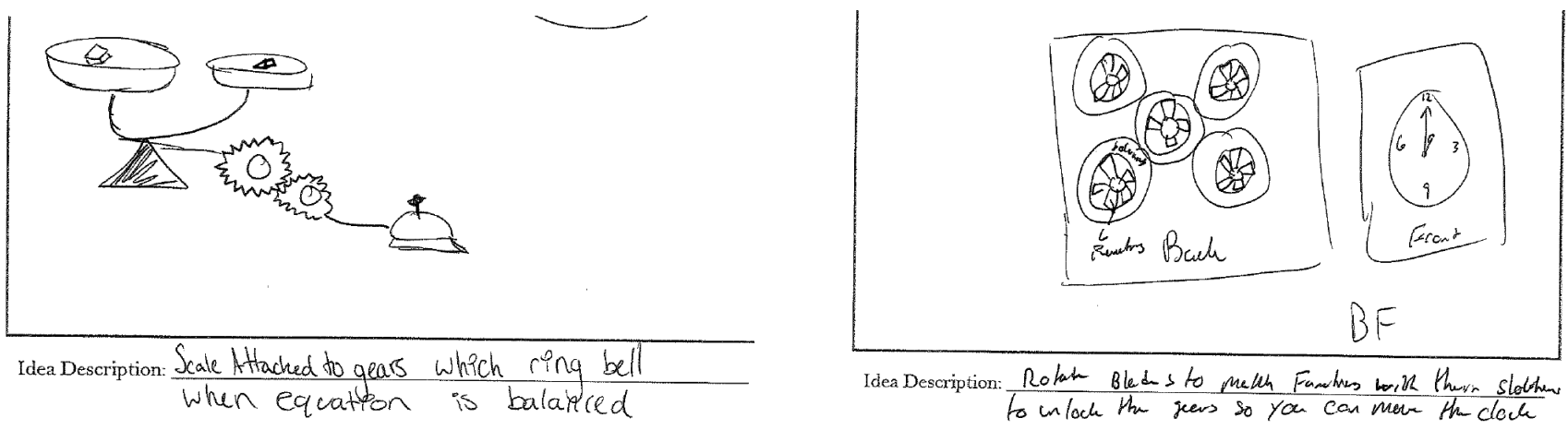

Figure 4: Example Ideas from Participant 3 (left) and Participant 7 (right) 


\section{Conclusions}

The purpose of this paper was to provide research-based evidence on how to deploy product dissection modules in engineering education and to translate these findings into an educational intervention. The case study presented here offers evidence on the utility of the module in a classroom environment. However, the case study also highlights key areas to stress in the discussion of the outcomes of the module. First, the product selected for dissection greatly impacts its perceived usefulness in the design task. The case study provides evidence of the type of discussion that can occur in the classroom environment on the variety of experiences students have when trying to come up with ideas after dissection and how this relates to the type of product dissected. In addition, although the modules were seen to be useful for the students in terms of understanding how the product works and inspiring creativity, the design problem used during the module can impact the utility of the dissection activity. The current models on the product dissection website were selected for tasks that contain an electrical or mechanical component. When presenting the module in an educational setting, it may be beneficial to have students work on a variety of design tasks and discuss how the products applied to the design task they had. This provides an additional means of discussion. Although the module described here and the research it is based on supports the use of these modules in engineering education, future work is still needed to optimize the modules. Specifically, future work will be geared at examining both student opinions of the module, as well as faculty insights into the ease of deployment of the modules. Finally, additional CAD models will be added to the website in order to expand the utility of the modules across a wider degree of design problems.

\section{Acknowledgments}

This material is based upon work supported by the National Science Foundation under Grant No. 1463009. We would also like to thank our undergraduate research assistant Carolyn Reigel for their help in this project.

\section{Bibliography}

[1] R. Gavin, "' The Lion King" and" Hamlet": A Homecoming for the Exiled Child," The English Journal, vol. 85, no. 3, pp. 55-57, 1996.

[2] S. R. Herring, C. Chang, J. Krantzler, and B. P. Bailey, "Getting Inspired! Understanding How and Why Examples are Used in Creative Design Practice," in ACM SIGCHI Conference on Human Factors in Computing Systems, Boston, MA, 2009, pp. 1-10.

[3] S. D. Sheppard, "Mechanical dissection: An experience in how things work," in Engineering Education: Curriculum Innovation \& Integration, Santa Barbara, CA, 1992, pp. 1-8.

[4] M. Brereton, S. Sheppard, and L. Leifer, "How Students Connect Engineering Fundamentals to Hardware Design: Observations and Implications for the Design of Curriculum and Assessment Methods," in the 10th International Conference on Engineering Design, Prague, WDK, 1995, vol. 23, pp. 336-342.

[5] J. S. Lamancusa, T. M. Kumar, and J. Jorgensen, "Learning engineering by product dissection," presented at the ASEE Annnual Conference, 1996. 
[6] J. S. Lamancusa, J. E. Jorgensen, and J. L. Zayas-Castro, "The learning factory-A new approach to integrating design and manufacturing into the engineering curriculum," Journal of Engineering Education, vol. 86, no. 2, pp. 103-112, 1997.

[7] A. H. Hande, W; Bakarat, N; Carrol, M, "Product Dissection: An Important Tool for a First Year Introduction to Engineering Course Project," presented at the ASEE North Central Conference, Ada, OH, April 7-8, 1005, 2005.

[8] T. E. Doyle, B. W. Baetz, and B. Lopes, "First-year engineering bicycle dissection as an introduction to sustainable design," presented at the Canadian Engineering Education Association, St. John's, Newfoundland, June 6-8, 2011, 2011.

[9] A. F. McKenna, W. Chen, and T. Simpson, "Exploring the impact of virtual and physical dissection activities on students's understanding of engineering design principles," presented at the ASME Design Engineering Technical Conferences, Brooklyn, NY, August 3-6, 2008, 2008.

[10] A. F. McKenna, W. Chen, and T. Simpson, "Exploring the impact of virtual and physical dissection activities on students's understanding of engineering design principles," in ASME IDETC/CIE, Brooklyn, NY, 2008, pp. 359-368: ASME.

[11] M. Borrego, J. E. Froyd, and T. S. Hall, "Diffusion of Engineering Education Innovations: A Survey of Awareness and Adoption Rates in U.S. Engineering Departments," Journal of Engineering Education, vol. 99, no. 3, pp. 185-207, 2010.

[12] M. Devendorf, K. Lewis, T. W. Simpson, T. W. Stone, R. B. Stone, and W. C. Regil, "Evaluating the use of digital product repositories to enhance product dissection activities in the classroom," Journal of Mechanical Design, vol. 9, 2010.

[13] T. W. Simpson, K. E. Lewis, R. B. Stone, and W. C. Regli, "Using Cyberinfrastructure to Enhance Product Dissection in the Classroom," presented at the Industrial Engineering Research Conference, Nashville, TN, May 19-23, 2007.

[14] M. Devendorf, K. Lewis, T. W. Simpson, R. B. Stone, and W. C. Regli, "Evaluating the Use of Cyberinfrastructure in the classroom to enhance product dissection," presented at the Design Engineering Technical Conferences, Las Vegas, Nevada, September 4-7, 2007.

[15] D. M. Divakaran and M. Gurusamy, "Towards flexible guarantees in clouds: Adaptive bandwidth allocation and pricing," IEEE Transactions on Parallel and Distributed Systems, vol. 26, no. 6, pp. 1754-1764, 2015.

[16] J. E. Jorgensen, J. L. Fridley, and J. S. Lamancusa, "Product dissection - a tool for benchmarking in the process of teaching design," in Frontiers in Education Conference, Salt Lake City, Utah, 1996, vol. 3, pp. 1317-1321: IEEE.

[17] K. Wood, D. Jensen, J. Bezdek, and K. Otto, "Reverse Engineering and Redesign: Courses to Incrementally and Systematically Teach Design," Journal of Engineering Education, vol. 90, no. 3, pp. 363-374, 2001.

[18] K. Grantham, G. Okudan, T. W. Simpson, and O. Ashour, "A Study on Situated Cognition: Product Dissection's Effect on Redesign Activities," presented at the Design Engineering Technical Conferences, Quebec, Canada, 2010.

[19] C. Toh and S. R. Miller, "Exploring the utility of product dissection for early-phase idea generation," in ASME IDETC/CIE, Portland, OR, 2013, pp. 1-12: ASME.

[20] C. Toh and S. R. Miller, "Product Dissection or Visual Inspection? The Impact of Designer-Product Interactions on Engineering Design Creativity," in ASME IDETC/CIE, Portland, OR, 2013: ASME. 
[21] T. Brown, "Design Thinking," Harvard Business Review, vol. June 2008, p. 10, 2008.

[22] C. L. Dym, A. M. Agogino, O. Eris, D. D. Frey, and L. J. Leifer, "Engineering design thinking, teaching, and learning," Journal of Engineering Education, vol. 94, no. 1, pp. 103-120, 2005.

[23] L. H. Jamieson and J. R. Lohmann, "Innovation with impact: Creating a culture for scholarly and systematic innovation in engineering education," in "American Society for Engineering Education, Washington," ASEE2012.

[24] T. C. McAloone, "A competence-based approach to sustainable innovation teaching: Experiences within a new engineering program," Journal of Mechanical Design, vol. 129, no. 7, pp. 769-778, 2007.

[25] N. Genco, K. Holtta-Otto, and C. C. Seepersad, "An Experimental Investigation of the Innovation Capabilities of Undergraduate Engineering Students," Journal of Engineering Education, vol. 101, no. 1, pp. 60-81, 2012.

[26] R. E. West, I. Tateishi, G. A. Wright, and M. Fonoimoana, "Innovation 101: Promoting undergraduate innovation through a two-day boot camp," Creativity Research Journal, vol. 24, no. 2-3, pp. 243-251, 2012.

[27] C. Toh, S. Miller, and T. Simpson, "The impact of virtual product dissection environments on student design learning and self-efficacy," Journal of Engineering Design, vol. 26, no. 1-3, pp. 48-73, 2015.

[28] P. Tierney and S. M. Farmer, "Creative self-efficacy: Its potential antecedents and relationship to creative performance," Academy of Management Journal, vol. 45, no. 6, pp. 1137-1148, 2002.

[29] F. Pajares, "Self-efficacy beliefs in academic settings," Review of educational research, vol. 66, no. 4, pp. 543-578, 1996.

[30] E. M. Starkey, A. S. McKay, S. T. Hunter, and S. R. Miller, "Piecing Together Product Dissection: How Dissection Conditions Impact Student Learning and Cognitive Load," Journal of Mechanical Design, vol. 140, no. 5, April 20182018.

[31] E. M. Starkey, S. T. Hunter, and S. R. Miller, "Are Creativity and Self-Efficacy At Odds? an Exploration in Variations Of Product Dissection in Engineering Education," Journal of Mechanical Design, 2018.

[32] M. Alsager Alzayed, C. McComb, S. T. Hunter, and S. R. Miller, "Expanding the Solution Space in Engineering Design Education: A Simulation-Based Investigation of Product Dissection," Journal of Mechanical Design, vol. 141, no. 3, 2019.

[33] E. M. Starkey, M. A. Alzayed, S. T. Hunter, and S. R. Miller, "Confidently Exploring The Solution Space: The Within-Subject Effects Of Product Dissection On Design Variety And Creative Self-Efficacy," in ASME IDETC/CIE, Quebec, Canada, 2018: ASME.

[34] D. S. S. Corporation, "eDrawings Viewer," ed, 2019.

[35] J. Guildford, P. Christensen, P. Merrifield, and R. Wilson, "Alternate uses: Manual of instructions and interpretation," Orange, CA: Sheridan Psychological Services, 1978. 
Appendix A - Supporting material for cost analysis of virtual and physical models

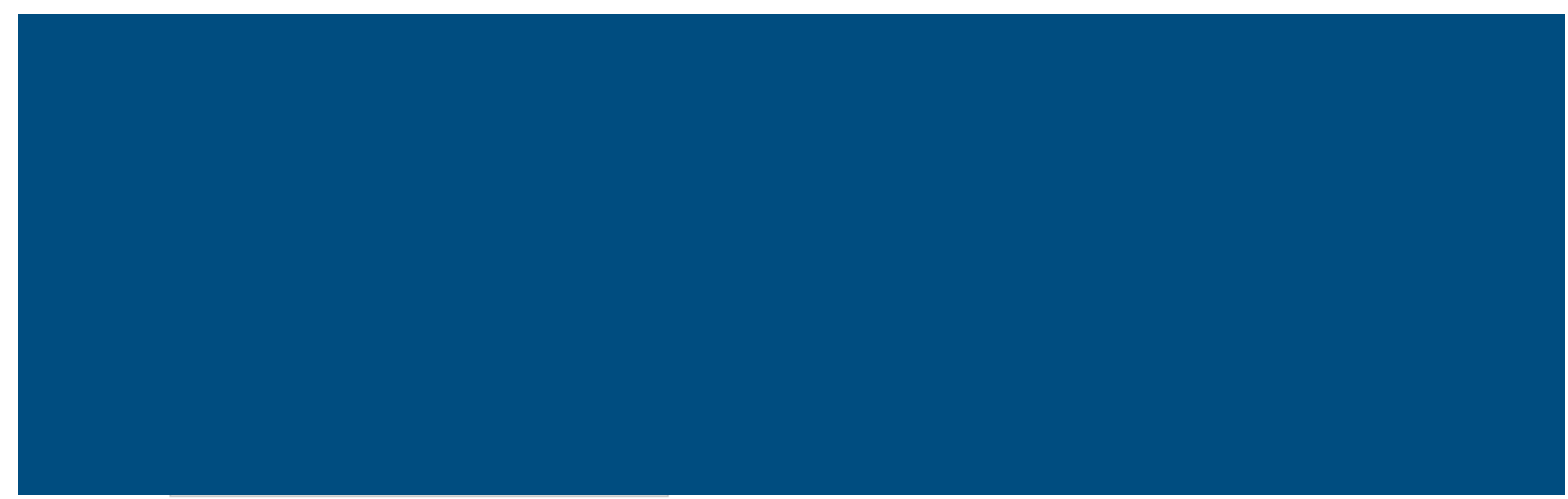

\begin{tabular}{|l|l|l|}
\hline ESTIMATE\# & DATE & EXPIRATION DATE \\
\hline A18021410 & $07 / 04 / 2018$ & $07 / 31 / 2018$ \\
\hline
\end{tabular}

PROJECT ADVISOR

Richman Siansimbi

\section{NET TERMS}

0

\begin{tabular}{|c|c|c|c|}
\hline DESCRIPTION & QTY & RATE & AMOUNT \\
\hline $\begin{array}{l}\text { 3D Scanning } \\
\text { Project Name: Part } 1 \\
\text { - 3D-Scanning, generating a point cloud/mesh and report a } \\
\text {.STL Files or .OBJ (Color if needed/requested). } \\
\text { - 3D Scanning Accuracy range: } 0.03 \mathrm{~mm}(0.001 ") \text { to } 0.1 \mathrm{~mm} \\
(0.004 ") \text {. }\end{array}$ & 1 & 285.00 & 285.00 \\
\hline $\begin{array}{l}\text { 3D Scanning } \\
\text { Project Name: Part } 2 \\
\text { - 3D-Scanning, generating a point cloud/mesh and report a } \\
\text {.STL Files or .OBJ (Color if needed/requested). } \\
\text { - 3D Scanning Accuracy range: } 0.03 \mathrm{~mm}(0.001 ") \text { to } 0.1 \mathrm{~mm} \\
(0.004 ") \text {. }\end{array}$ & 1 & 235.00 & 235.00 \\
\hline $\begin{array}{l}\text { 3D Scanning } \\
\text { Project Name: Part } 3 \\
\text { - 3D-Scanning, generating a point cloud/mesh and report a } \\
\text {.STL Files or .OBJ (Color if needed/requested). } \\
\text { - 3D Scanning Accuracy range: } 0.03 \mathrm{~mm}(0.001 ") \text { to } 0.1 \mathrm{~mm} \\
(0.004 ") \text {. }\end{array}$ & 1 & 285.00 & 285.00 \\
\hline $\begin{array}{l}\text { 3D Scanning } \\
\text { Project Name: Part } 4 \text { (Black) } \\
\text { - 3D-Scanning, generating a point cloud/mesh and report a } \\
\text {.STL Files or .OBJ (Color if needed/requested). } \\
\text { - 3D Scanning Accuracy range: } 0.03 \mathrm{~mm}(0.001 ") \text { to } 0.1 \mathrm{~mm} \\
(0.004 ") \text {. }\end{array}$ & 1 & 195.00 & 195.00 \\
\hline $\begin{array}{l}\text { 3D Scanning } \\
\text { Project Name: Part } 5,6,7,8,10,11,13 \\
\text { - 3D-Scanning, generating a point cloud/mesh and report a } \\
\text {.STL Files or .OBJ (Color if needed/requested). } \\
\text { - 3D Scanning Accuracy range: } 0.03 \mathrm{~mm}(0.001 ") \text { to } 0.1 \mathrm{~mm} \\
(0.004 ") \text {. }\end{array}$ & 7 & 185.00 & $1,295.00$ \\
\hline
\end{tabular}




\begin{tabular}{|c|c|c|c|}
\hline DESCRIPTION & QTY & RATE & AMOUNT \\
\hline $\begin{array}{l}\text { 3D Scanning } \\
\text { Project Name: Part } 12,14 \\
\text { - 3D-Scanning, generating a point cloud/mesh and report a } \\
\text { STL Files or .OBJ (Color if needed/requested). } \\
\text { - 3D Scanning Accuracy range: } 0.03 \mathrm{~mm}(0.001 ") \text { to } 0.1 \mathrm{~mm} \\
\text { (0.004"). }\end{array}$ & 2 & 285.00 & 570.00 \\
\hline $\begin{array}{l}\text { Reverse Engineering } \\
\text { PROJECT NAME: Part 1, } 3 \\
\text { Ensing the Scanned Data as a reference to Reverse } \\
\text { Engineer } \\
\text { (theoretically perfect and symmetrical) for machining. } \\
\text { Reconstruction of the surfaces/solids with a design intent } \\
\text { Software. } \\
\text { - Deliverable: .STEP/IGES unless otherwise noted. }\end{array}$ & 2 & 385.00 & 770.00 \\
\hline $\begin{array}{l}\text { Reverse Engineering } \\
\text { PROJECT NAME: Part 2, 4, 5, 6, 8, 9, } 12,14 \\
\text { - Using the Scanned Data as a reference to Reverse } \\
\text { Engineer } \\
\text { - Reconstruction of the surfaces/solids with a design intent } \\
\text { (theoretically perfect and symmetrical) for machining. } \\
\text { Creation of the CAD model compatible with any CAD } \\
\text { Software. } \\
\text { - Deliverable: .STEP/IGES unless otherwise noted. }\end{array}$ & 7 & 285.00 & $1,995.00$ \\
\hline $\begin{array}{l}\text { Reverse Engineering } \\
\text { PROJECT NAME: Part } 10,11,13 \text {, } \\
\text { - Using the Scanned Data as a reference to Reverse } \\
\text { Engineer } \\
\text { - Reconstruction of the surfaces/solids with a design intent } \\
\text { (theoretically perfect and symmetrical) for machining. } \\
\text { Creation of the CAD model compatible with any CAD } \\
\text { Software. } \\
\text { - Deliverable: .STEP/IGES unless otherwise noted. } \\
\text { ETA } \\
\text { Delivery } \\
-5 \text { to } 10 \text { business days }\end{array}$ & 3 & 185.00 & 555.00 \\
\hline $\begin{array}{l}\text { Notes } \\
\text { This quotation is based on the part \#s highlighted in the image. }\end{array}$ & & & \\
\hline
\end{tabular}

If you have any questions/concerns, please don't hesitate to let us know. TOTAL 


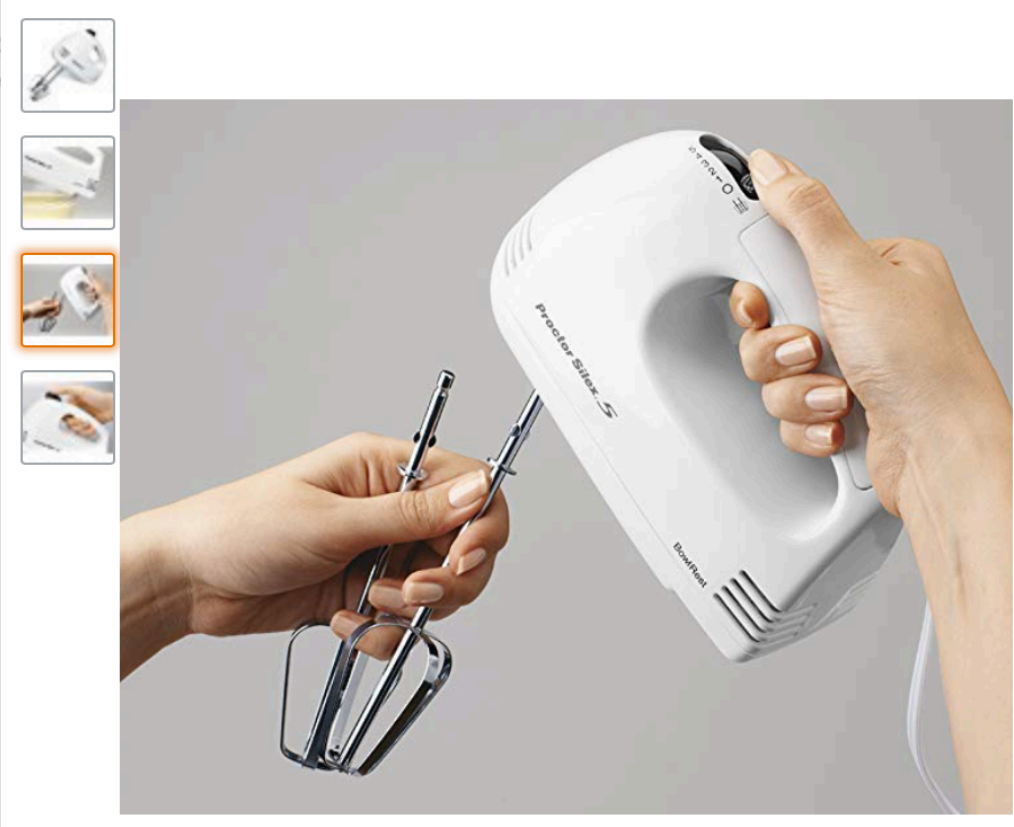

Roll over image to zoom in
Proctor Silex

Proctor Silex 62509RY 5Speed Hand Mixer, White

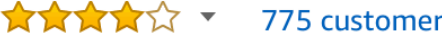
reviews

| 24 answered questions

List Price: $\$ 19.99$

Price: \$14.89 vprime

a FREE One-Day Pickup. Details

You Save: $\$ 5.10$ (26\%)

Get $\$ 70$ off instantly: Pay $\$ 0.00$ upon approval for the Amazon Prime Rewards Visa Card.

- Convenient Bowl rest feature

- 100-WattS of power

- Beater eject button

- 5 Speeds for several mixing options

- Full sized chrome beaters 